\title{
Photosynthetic responses in Phaeocystis antarctica towards varying light and iron conditions
}

\author{
M. A. van Leeuwe $\cdot$ J. Stefels
}

Received: 23 March 2006/ Accepted: 10 August 2006/Published online: 23 March 2007

(C) Springer Science+Business Media B.V. 2007

\begin{abstract}
The effects of iron limitation on photoacclimation to a dynamic light regime were studied in Phaeocystis antarctica. Batch cultures were grown under a sinusoidal light regime, mimicking vertical mixing, under both iron-sufficient and -limiting conditions. Iron-replete cells responded to changes in light intensity by rapid xanthophyll cycling. Maximum irradiance coincided with maximum ratios of diatoxanthin/diadinoxanthin (dt/dd). The maximum quantum yield of photosynthesis $\left(F_{v} / F_{m}\right)$ was negatively related to both irradiance and $\mathrm{dt} / \mathrm{dd}$. Full recovery of $F_{v} / F_{m}$ by the end of the light period suggested successful photoacclimation. Iron-limited cells displayed characteristics of high light acclimation. The ratio of xanthophyll pigments to chlorophyll $a$ was three times higher compared to iron-replete cells. Down-regulation of photosynthetic activity was moderated. It is argued that under iron limitation cells maintain a permanent state of high energy quenching to avoid photoinhibition during exposure to high irradiance. Iron-limited
\end{abstract}

M. A. van Leeuwe

Department of Marine Biology, Biological Centre, University of Groningen, Haren, The Netherlands

J. Stefels $(\bowtie)$

Laboratory for Plant Physiology, Biological Centre,

University of Groningen, P. O. Box 14,

Haren 9750 AA, The Netherlands

e-mail: j.stefels@rug.nl cells could maintain a high growth potential due to an increased absorption capacity as recorded by in vivo absorption, which balanced a decrease in $F_{v} / F_{m}$. The increase in the chlorophyll $a$ specific absorption cross section was related to an increase in carotenoid pigments and a reduction in the package effect. These experiments show that $P$. antarctica can acclimate successfully to conditions as they prevail in the Antarctic ocean, which may explain the success of this species.

Keywords Fluorescence · Iron · Light ·

Phaeocystis $\cdot$ Pigments - Xanthophyll cycling

\section{Introduction}

In the Southern Ocean, the factors light and iron exert synergistic growth control on microalgae (De Baar et al. 2005). In vast areas, iron concentrations are often too low to support growth (Martin et al. 1990; van Leeuwe et al. 1997). In addition, frequent wave action induces deep vertical mixing of the water column. Consequently, its planktonic inhabitants are subject to a highly dynamic light regime (Mitchell and Brody 1991). Under these conditions, the ability to photoacclimate determines the growth success of algae. Since iron exerts control on various photosynthetic processes, its low ambient 
concentration may impede photoacclimation (Greene et al. 1991; van Leeuwe and De Baar 2000). Yet, the impact of iron limitation on photoacclimation has so far received little attention.

Photoacclimation to a dynamic light regime involves optimisation of the photosystems in such a way that energy generation and utilisation are in balance (Kana et al. 1997). Conditions of rapid vertical mixing require that cells can acclimate directly to changes in light intensity that range from almost darkness to excessively high irradiance levels. Dim light conditions deep in the water column necessitate an extensive light-harvesting complex, whereas high irradiance levels at the surface require small complexes that are resistant to photodamage. When more energy is generated than can be utilised for growth, photodamage can occur (Demmig-Adams and Adams 1996). Under variable light conditions, periods between low- and high-light conditions are usually too short for acclimation by de novo synthesis of light-harvesting or photoprotective pigment-protein complexes, respectively. Moreover, de novo synthesis is a costly process. Cells that are subjected to variable light conditions will therefore benefit from flexible photosystems (see Muller et al. 2001 for review). Processes involved in photoacclimation on short time scales (minutes) are energy-dependent quenching (qE) and state-transition quenching (qT). These processes vary with species (e.g. van Leeuwe et al. 2005). Green flagellates possess adaptable photosystems that support the rapid down-regulation of photosynthetic activity by xanthophyll pigment cycling and state transitions. In these organisms, alternative quenching processes that involve mobility of the photosynthetic membranes (Anderson et al. 1995) may also play a role, but are not well described. In contrast, rapid photoacclimation in diatoms is limited to xanthophyll cycling. This appears to be related to a more-homogeneous, and therefore less-flexible, organisation of the thylakoid membranes of diatoms (Larkum et al. 2003).

The make-up of the photosynthetic apparatus and consequently to the capacity of photoacclimation depends on the availability of iron. Previously it has been found that iron-limited cells contain less chlorophyll $a$, but relatively more photoprotective pigments (Geider et al. 1993; van Leeuwe and Stefels 1998; van Leeuwe and De Baar 2000). In addition, various protein-pigment complexes that constitute the photosystems require iron for synthesis (cytochromes and $\mathrm{FeS}$ proteins). Under iron limitation, impairment of those protein complexes results in a decrease in the efficiency of electron transport (Greene et al. 1991). Experiments that were carried out under low, stable light conditions showed that while iron limitation resulted in a reduction in photosynthetic efficiency, the absorption efficiency had increased due to a reduction in the package effect (Greene et al. 1991; van Leeuwe and De Baar 2000). Accordingly, iron-limited cells were acclimated to low irradiance to a large extent. However, nothing is known about the effects of iron limitation on the photosynthetic response towards variable light conditions. A disorder in the architecture of the photosynthetic membranes may have negative consequences for the flexibility of the photosystems through constraining effects on the coupling and decoupling of pigment-protein complexes that are involved in xanthophyll cycling (Muller et al. 2001). Even so, alternative quenching processes that depend on conformational changes of membrane proteins are likely to be disturbed.

So far, few studies addressed photoacclimation to rapidly changing light conditions. The data that are available show that diatoms acclimate to the average irradiance levels they encounter. Under variable light conditions, this strategy has negative consequences for their growth success as it makes the algae more susceptible to photoinhibition when exposed to high irradiance levels (Flameling and Kromkamp 1995; Flameling 1998, van Leeuwe et al 2005). No studies are currently available on the effects of iron limitation on photoacclimation towards a variable light regime. Here, we present the first data on photosynthetic responses by the marine microalga Phaeocystis antarctica towards varying conditions of light and iron availability. P. antarctica is abundant in the Southern Ocean, and it plays a prominent role in various biogeochemical cycles (Smith et al. 1998; Arrigo et al. 1999; Vaillancourt et al. 2003). The alga may form massive 
blooms that can potentially sequester $\mathrm{CO}_{2}$ from the atmosphere. In addition, $P$. antarctica is known for its production of dimethylsulphide (DMS), a semivolatile sulphur compound that once it has escaped into the atmosphere induces cloud formation thus affecting the global climate system (Crocker et al. 1995; Stefels and van Leeuwe 1998). The success of Phaeocystis as a cosmopolitan species is still not well understood. Previously, rapid photophysiological acclimation was found in P. antarctica (Moisan et al. 1998; van Leeuwe and Stefels 1998; Moisan and Mitchell 1999). These studies were performed under stable light conditions and they only partly explain its success in the open ocean areas that are characterised by highly dynamic light conditions (Mitchell and Brody 1991). Here we will show that $P$. antarctica can be so abundant in the Southern Ocean because of its high capacity to acclimate its photosystems to ambient irradiance levels, even under conditions of iron limitation. Photosynthetic efficiency was recorded by means of dualmodulation fluorescence analysis. Analysis of the pigment composition and recording of in vivo absorption spectra were used to determine responses of the antennae complex.

\section{Methods}

\section{Culture conditions}

Phaeocystis antarctica (CCMP 1871; non-axenic) was cultured under dynamic light conditions simulating vertical mixing through the water column. The light regime was enforced by a Venetian Blind system that was mounted between the cultures and the light source (Philips MHNTD). The system consisted of horizontal slats the position of which could be altered by a step motor. Two independent units were used to enforce variable light conditions; the diurnal intensity of solar irradiance was simulated by a sinusoidal light course. Vertical mixing was simulated by a second oscillation that was superimposed on the solar pattern (see Fig. 1). The maximum intensity of irradiance was $400 \mu \mathrm{mol}$ photons $\mathrm{m}^{-2} \mathrm{~s}^{-1}$. The light inside the culture flasks was measured with a spherical sensor (Biosperical Instruments Inc. QSL-100). The cultures were grown in $2 \mathrm{~L}$ polycarbonate erlenmeyer flasks at $4^{\circ} \mathrm{C}$ and kept in suspension by daily shaking. Medium was prepared as described by Morel et al. (1979). Chelexed, nutrient-poor seawater originating from the Atlantic sector of the Southern Ocean was enriched with $140 \mu \mathrm{M} \mathrm{NO}$, $7.5 \mu \mathrm{M} \mathrm{P_{4 }}$ and $60 \mu \mathrm{M}$ Si. Solutions of $\mathrm{FeCl}_{3}$ and ethylenediaminetetraacetic acid (EDTA) were added separately at final concentrations of $10^{-6} \mathrm{M}$ EDTA for all cultures and $10^{-6} \mathrm{M}$ iron for iron-rich cultures. Initial iron concentrations (measured by solvent extraction followed by atomic absorption spectrophotometry; Nolting and de Jong 1994) were $15 \mathrm{nM}$. Before starting the experiments, cultures were stressed by iron deficiency and adapted to light conditions for several weeks. During that period, the main growth form of the cells had gradually changed: the iron-limited cultures consisted mainly of single cells; the iron-replete cultures consisted mainly of colonies.

\section{Photosynthetic parameters}

Chlorophyll $a$ fluorescence was measured with a dual-modulated fluorometer (Photosystem Instruments, Trtílek et al. 1997). Minimum $\left(F_{o}\right)$ and maximum fluorescence $\left(F_{\mathrm{m}}\right)$ was recorded after dark adaptation $\left(5 \mathrm{~min}\right.$ at $4^{\circ} \mathrm{C}$, sufficient to attain stabilization of the fluorescence signal for all light regimes). The maximum quantum yield of photosynthesis $F_{v} / F_{m}$ was calculated as $\left(F_{m}-F_{o}\right) / F_{m}$ (Krause and Weis 1991).

Samples for pigment analysis were filtered gently $(<15 \mathrm{KPa})$ over Whatman $\mathrm{GF} / \mathrm{F}$ filters and subsequently snap-frozen in liquid nitrogen and stored at $-80^{\circ} \mathrm{C}$ until analysis. Before extraction in $90 \%$ acetone filters were freeze-dried during $48 \mathrm{~h}$. Pigments were analysed by highperformance liquid chromatography on a Waters system equipped with a photodiode array (van Leeuwe et al. 2006). A Waters DeltaPak reversed-phase column (C18, fully end-capped) was used. Pigment standards were obtained from the DHI Water Quality Institute (Horsholm, Denmark). 
In vivo light absorption spectra (400-700 nm) were recorded with a Varian-Cary spectrophotometer equipped with an integrating sphere. Samples were taken to an approximate optical density of 0.1. Data were corrected for scattering by subtracting a baseline value as measured at $725 \mathrm{~nm}$. The spectrally averaged, chlorophyll $a$ specific absorption cross section $\left(\overline{\mathrm{a}}_{\mathrm{ph}}, \mathrm{m}^{2} \mathrm{mg}\right.$ Chl $a^{-1}$ ) was calculated as follows:

$$
\overline{\mathrm{a}}_{\mathrm{ph}}=\frac{\int_{400}^{700} a_{\operatorname{chl}}(\lambda) * Q(\lambda) \delta(\lambda)}{\int_{400}^{700} Q(\lambda) \delta(\lambda)}
$$

where $a_{\mathrm{chl}}(\lambda)$ is the wavelength specific absorption $\left(\mathrm{m}^{2} \mathrm{mg} \mathrm{Chl} a^{-1}\right), Q(\lambda)$ is spectral irradiance of the light source ( $\mu \mathrm{mol}$ photons $\mathrm{m}^{-2} \mathrm{~s}^{-1}$ ) and $\delta(\lambda)$ is the wavelength interval of the spectral band $(2 \mathrm{~nm})$.

\section{Sampling strategy and statistical analyses}

All experiments were performed in duplicate. Samples for photosynthetic parameters were taken over the course of one day only (13 data points). A day was chosen during which cells were still growing exponentially while cell densities were high enough to allow reliable in vivo fluorescence measurements. Growth rates were established by cell counts in the days preceding the $24 \mathrm{~h}$ experiments. Cells were counted with an inverse microscope after settling for $24 \mathrm{~h}$ in a counting chamber. Effects of iron limitation on photosynthetic parameters (Table 2) were tested for significance by use of a two-factor analyses of variance. The daily dynamics of the photosynthetic parameters (Figs. 1-3) were tested for significance by multiple regression analyses. Differences were considered significant at $P<0.05$.

\section{Results}

The main pigments of Phaeocystis antarctica were chlorophyll $a$, chlorophyll $c_{1+2}$, fucoxanthins, diadinoxanthin and diatoxanthin. The ratio of the photoprotective xanthophyll pigments diadino- and diatoxanthin to chlorophyll $a$ was 0.229 in iron-limited cells and only 0.077 in iron-replete cells (Table 1). The ratio of $19^{\prime}$-hexanoyloxyfucoxanthin to chlorophyll $a$ was also higher under iron limitation: 0.734 versus 0.344 for iron-replete cells. Iron limitation resulted in $10 \%$ growth reduction (Table 2). The reduction in growth was associated to a $20 \%$ reduction in the maximum quantum yield of photosynthesis $\left(F_{v /} F_{m}\right)$ and
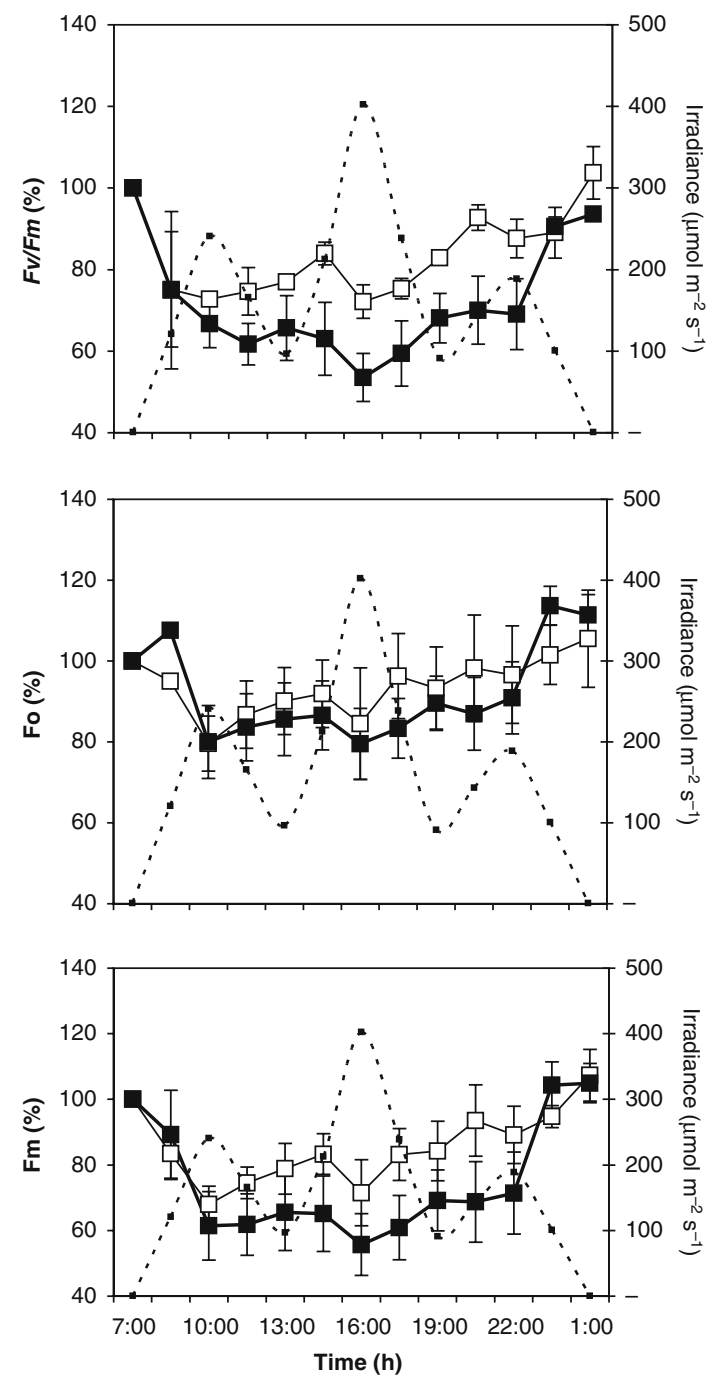

Fig. 1 Fluorescence characteristics of photosynthesis determined over the day for iron-limited (open symbols) and iron-replete cells (closed symbols), plotted alongside irradiance (photons $\mathrm{m}^{-2} \mathrm{~s}^{-1}$; dashed line). Fluorescence dynamics are expressed in percentages, taking the maximum morning values as reference (i.e. $100 \%$; $n=3$ ). (A) Maximum quantum yield of fluorescence $\left(F_{v} / F_{m}\right)$. (B) Minimum fluorescence $\left(F_{o}\right)$. (C) Maximum fluorescence $\left(F_{m}\right)$ 
Table 1 The pigment composition of Phaeocystis antarctica for iron-limited and iron-replete cells, expressed as ratios to chlorophyll $a(n=3)$ (average values \pm s.d.)

\begin{tabular}{lllll}
\hline Ratio to Chl $a$ & Fe-limited & \pm s.d. & Fe-replete & \pm s.d. \\
\hline Chlorophyll $c 3$ & 0.116 & 0.012 & 0.091 & 0.009 \\
Chlorophyll $c 2$ & 0.197 & 0.017 & 0.202 & 0.013 \\
19'-Butanoyloxyfucoxanthin & 0.013 & 0.003 & 0.009 & 0.003 \\
Fucoxanthin & 0.011 & 0.004 & 0.344 & 0.009 \\
19'-Hexanoyloxyfucoxanthin & 0.734 & 0.021 & 0.057 & 0.120 \\
Diadinoxanthin & 0.214 & 0.037 & 0.025 & 0.048 \\
Diatoxanthin & 0.017 & 0.012 & 0.009 & 0.024 \\
Zeaxanthin & 0.026 & 0.002 & 0.014 & 0.003 \\
Beta-carotene & 0.016 & 0.004 & 0.381 & 0.007 \\
Total fucos* & 0.760 & 0.025 & 0.077 & 0.065 \\
Diadino-plus diatoxanthin & 0.229 & 0.044 & \\
\hline
\end{tabular}

* 19'-Butanoyloxyfucoxanthin + Fucoxanthin $+19^{\prime}-$ Hexanoyloxyfucoxanthin

Table 2 Photosynthetic parameters of Phaeocystis antarctica for iron-limited and iron-replete cells $(n=3)($ average values \pm s.d.)

\begin{tabular}{|c|c|c|c|c|c|c|c|c|c|c|}
\hline & $\mu\left(\mathrm{d}^{-1}\right)$ & \pm s.d. & $F_{v} / F_{m}^{\mathrm{a}}$ & \pm s.d. & $\begin{array}{l}\text { Chlorophyll } \\
a\left(\mathrm{pg} \text { cell }^{-1}\right)\end{array}$ & \pm s.d. & $\begin{array}{l}\overline{\mathrm{a}}_{\mathrm{ph}} \\
\left(\mathrm{m}^{2} \mathrm{mg} \mathrm{Ch}{ }^{-1}\right)\end{array}$ & \pm s.d. & $\begin{array}{l}\mathrm{POC}^{\mathrm{b}} \\
\left(\mathrm{pg} \mathrm{cell}^{-1}\right)\end{array}$ & $\operatorname{rgc}^{\mathrm{c}}$ \\
\hline Fe-limited & 0.49 & 0.02 & 0.40 & 0.04 & 0.08 & 0.02 & 0.057 & 0.023 & 14 & 0.13 \\
\hline Fe-replete & 0.55 & 0.07 & 0.50 & 0.02 & 0.15 & 0.03 & 0.030 & 0.022 & 19 & 0.12 \\
\hline
\end{tabular}

Differences between the treatments were significant [analysis of variations (ANOVA) $P<0.05$ ]) for all parameters

a Morning values

b Data from Stefels and van Leeuwe (1998)

c Relative growth capacity, see discussion for details

almost $50 \%$ decrease in cellular chlorophyll $a$ content (Table 2, Fig. 4).

The $F_{v} / F_{m}$ of 0.5 recorded for iron-replete cells was close to the maximum values measured in our lab, though they are lower than the values reported for natural populations that were dominated by Phaeocystis antarctica (Vaillancourt et al. 2003). Whereas our cultures were in good condition, the experimental conditions provided were certainly not the most optimal for growth $P$. antarctica. Maximum values for $F_{v} / F_{m}$ were in fact achieved at more stable light conditions (pers. obs.).

The maximum quantum yield of photosynthesis $\left(F_{v} / F_{m}\right)$ varied with daily dynamics in light intensity in both the iron-limited and iron-replete cells (Fig. 1A). Maximum values were recorded in the morning, followed by decreasing values towards the middle of the light period. In replete cells, the midday depression was almost $50 \%$ of the morning values; $F_{v} / F_{m}$ decreased by about $30 \%$ under iron limitation. The $F_{v} / F_{m}$ recovered towards the end of the light period (significant relationship between irradiance and $F_{v} / F_{m} ;$ ANOVA, $\left.P<0.05\right)$. Depressions in irradiance coincided with moderate increases in the fluorescence parameters. Minimum $\left(F_{o}\right)$ and maximum $\left(F_{m}\right)$ fluorescence values varied along with $F_{v} / F_{m}$ (Fig. $\left.1 \mathrm{~B}, \mathrm{C}\right)$. The dynamics were most pronounced for the maximum fluorescence signal in iron-replete cells.

In concordance with the diel dynamics in $F_{v} / F_{m}$, active xanthophyll cycling was observed over the day (Fig. 2A, B). The ratio of diatoxanthin (dt) to diadinoxanthin (dd) was closely linked to irradiance, with maximum conversion of $\mathrm{dd}$ into dt recorded during maximum irradiance. Whereas the total pool of $\mathrm{dd}+\mathrm{dt}$ was highest in iron-limited cells (Table 1 ), the $\mathrm{dt} / \mathrm{dd}$ ratio was significantly higher in iron-replete cells: 0.9 versus 0.15 for Fe-limited cells (Fig. 2).

In iron-deplete cells, the pool of fucoxanthins was not stable over the day. The ratio of 19'-hexanoyloxyfucoxanthin to fucoxanthin 

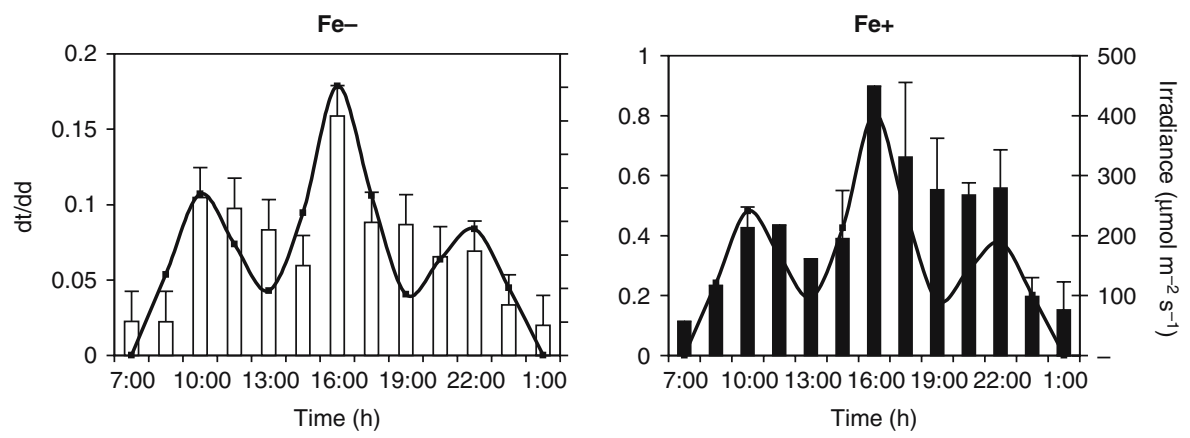

Fig. 2 Daily dynamics of the xanthophylls cycle (ratio of diadinoxanthin to diatoxanthin; dt:dd) plotted alongside irradiance (photons $\mathrm{m}^{-2} \mathrm{~s}^{-1}$; solid line). (A) Iron-limited cells. (B) Iron-replete cells
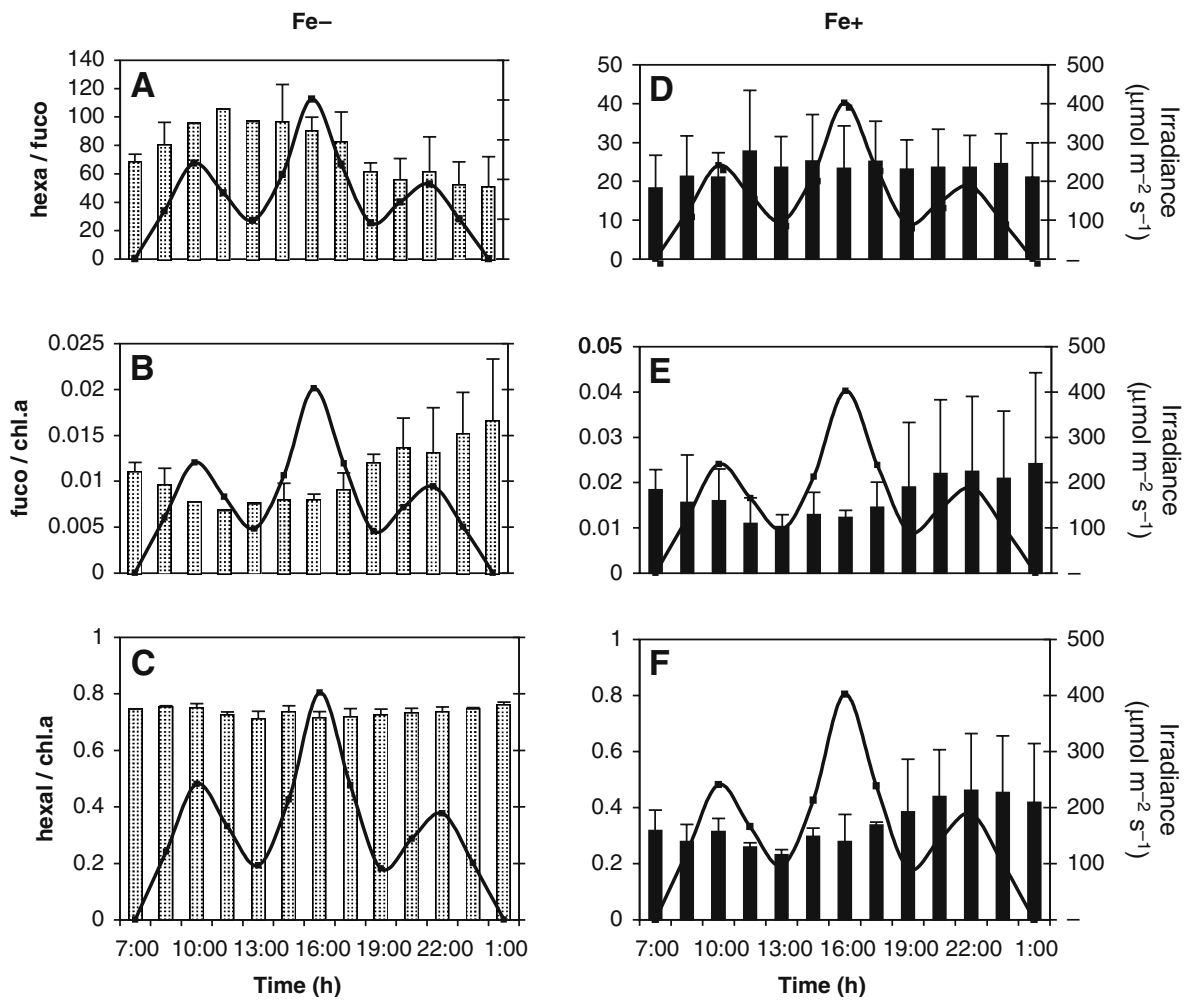

Fig. 3 Daily dynamics of the fucoxanthin pigments plotted alongside irradiance (photons $\mathrm{m}^{-2} \mathrm{~s}^{-1}$; solid line) in ironlimited $(\mathrm{Fe}-)$ and iron-replete $(\mathrm{Fe}+)$ cells. $(\mathbf{A}, \mathbf{D})$ Ratio of

19'-hexanoyloxyfucoxanthin to fucoxanthin (hexa/fuco). $(\mathbf{B}, \mathbf{E})$ Ratio of fucoxanthin to chlorophyll $a$. (C, F) Ratio of $19^{\prime}$ hexanoyloxyfucoxanthin to chlorophyll $a$

In both treatments, the in vivo light absorption (HEXA/FUCO) decreased towards the end of the light period (Fig. 3A; $P<0.05$ ), which was associated with a $50 \%$ increase in $\mathrm{FUCO} / \mathrm{Chl} a$ (Fig. 3B), whereas HEXA/Chl $a$ remained invariable at a high level (Fig. 3C). In iron-replete cells, no significant daily dynamics in HEXA and FUCO were observed (Fig. 3D-F). characteristics were invariable over the day (data not shown). Maximum values in the chlorophyllspecific absorption coefficient were observed near $675 \mathrm{~nm}$ (Chl $a), 470 \mathrm{~nm}$ (carotenoids) and $430 \mathrm{~nm}$ (Chl $a$ ) (Fig. 4). The absorption cross section was $0.057 \mathrm{~m}^{2} \mathrm{mg}$ Chl $a^{-1}$ under iron limitation and 


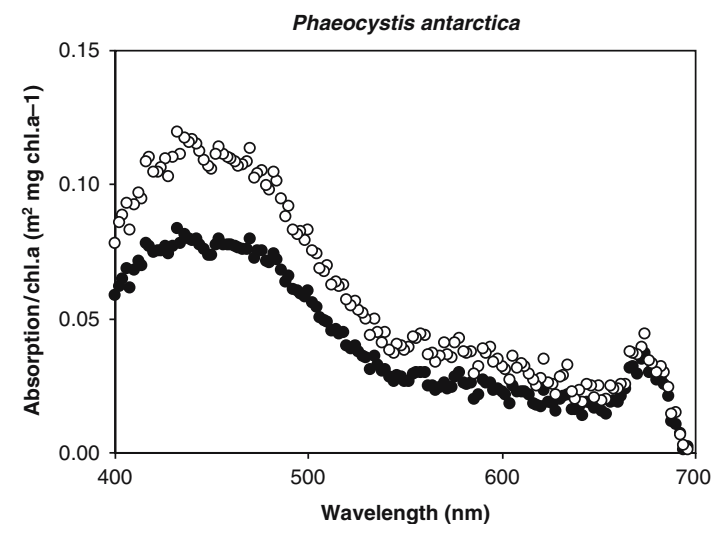

Fig. 4 In vivo absorption spectra expressed per chlorophyll $a$ for iron-limited (open symbols) and iron-replete cells (closed symbols)

almost two times lower in iron-replete cells (Table 2). Elevated values in the Soret region for iron-limited versus iron-replete cells reflected the relative increase in fucoxanthins and photoprotective pigments.

\section{Discussion}

Cells that are exposed to varying irradiance levels need to tune their photosynthetic apparatus in a way that allows optimal use of irradiance during exposure to the lower intensities and simultaneously find a way to avoid photoinhibition when subjected to high irradiance levels. On short time scales, xanthophyll pigment cycling plays an important role in photoacclimation to high irradiance (Olaizola et al. 1994). De-epoxidation of the light-harvesting pigment diadinoxanthin into the heat dissipating diatoxanthin requires only seconds to minutes, depending on the species. Until now, physiological studies on xanthophyll cycling mostly involved short-term experiments during which abrupt light shifts were applied. A role for xanthophyll cycling under conditions of continuous variations in light intensity only had been recorded in an Antarctic diatom and a green flagellate (van Leeuwe et al. 2005). Here we show that also in Phaeocystis antarctica, photoacclimation to variable light conditions is promoted by the xanthophyll pigments. A significant relationship was recorded between the de-epoxidation state of the xanthophyll pigments and the maximum quantum yield of photosynthesis $\left(F_{v} / F_{m}\right)$. Minimum values for $F_{v} / F_{m}$, coinciding with increasing irradiance, were mirrored by enhanced ratios of diato- to diadinoxanthin. The close relationship between the two parameters unequivocally establishes the role of the xanthophyll pigments in the down-regulation of photosynthetic activity. Daily dynamics in fluorescence signals have also been observed in experiments with cultures of $P$. globosa (Flameling and Kromkamp 1995). The authors could, however, not demonstrate a role for xanthophyll pigments. Possibly, in those experiments the levels in diatoxanthin were too low to determine accurately. A role for xanthophyll pigments in photoacclimation by Phaeocystis sp. has been shown for stable light conditions (Moisan et al. 1998; van Leeuwe and Stefels 1998; Meyer et al. 2000). Our study confirms these findings, and adds an active role in the regulation of photosynthesis under conditions of a-ecologically more relevant-dynamic light climate.

Since we worked in batch cultures and iron concentrations in the unamended media were at nanomolar levels, initial growth rates were only slightly reduced in the iron-limited cultures (Table 2). The addition of EDTA did not set this right; it appears as though Phaeocystis, amongst other algal species, might access EDTA-complexed iron (see Sedwick et al. 2006). Iron limitation was achieved in the course of time, as most clearly reflected in the photosynthetic parameters that were recorded during the final stages of exponential growth. A modest albeit significant reduction in $F_{v} / F_{m}$ was observed in iron-limited cells. The impact of nutrient limitation on this fluorescence parameter per se is under debate (see Kruskopf and Flynn 2006 and references therein). Yet, the daily dynamics provided the more important information. Down-regulation of $F_{v} / F_{m}$ was suppressed under iron limitation. The moderation in regulation was related to a weaker response in $F_{m}$ (Fig. 1). Iron limitation exerted a minor effect on $F_{0}$. These effects are most likely related to a reduction in xanthophyll pigment cycling. Although the patterns in de-epoxidation state were similar for both iron conditions, the conversion of dd into $\mathrm{dt}$ was relatively minor in 
iron-limited cells. The enlarged xanthophyll pool in iron-limited cells most probably compensated for the lower $\mathrm{dt} / \mathrm{dd}$ ratio, thereby maintaining a high level of heat dissipation throughout the day, with minor variations over the light period. This pattern characterises high light acclimated cells, which confirms a high susceptibility towards photoinhibition known for iron-limited cells (Geider and LaRoche 1994; Morales et al. 1998; van Oijen et al. 2004). In addition, it can be hypothesised that the single cell shape will have rendered iron-limited cells more sensitive to high irradiance compared to the colonial form that dominated under iron-replete conditions because of an increase in specific absorption (Morel and Bricaud 1981; Fujiki and Tagushi 2002).

Similar differences in pigment composition between iron-limited and iron-replete cells have previously been recorded for $P$. antarctica, albeit not under variable light conditions (van Leeuwe and Stefels 1998). When subject to a dynamic light regime, more energy has to be invested in an increased xanthophyll pool if the photosystems are not flexible enough to respond to rapid increases in irradiance level. We hypothesise that a loss in flexibility is related to a role of iron in the integrity and fluidity of photosynthetic membranes. Photochemical quenching by xanthophyll cycling ( $\mathrm{qE}$ ) involves conformational changes of the photosynthetic membranes (Mohanty et al. 1995; Pascal et al. 2005). These membranes are made up of various protein complexes in many of which iron plays an essential role. Under iron limitation, it appears that the conformation of the complexes themselves and of the membrane as a whole is impaired. As a result, membranes become less flexible and the necessary changes during xanthophyll cycling may be hampered.

The almost full recovery of $F_{v} / F_{m}$ under both iron conditions indicated successful photoacclimation. Damage to the photosystems can, however, not be excluded. Minor degradations will go by unnoticed when the rate of repair is sufficiently fast to sustain high rates of photochemistry (Morales et al. 1998; Han et al. 2000; Kana et al. 2002; van Leeuwe et al. 2005). The increased xanthophyll pool of iron-limited cells indicates that these cells experience an enhanced risk of photodamage, which could result in increased energy costs for repair. This exerts additional stress on iron-limited cells. Whereas iron-sufficient cells invest in larger photosystems (increased Chl $a$ per cell) in order to efficiently use the periods of low irradiance, iron-limited cells have to invest in a mechanism to prevent photodamage and at the same time maximise energy production. This is attained by a relative reduction of (iron-expensive) Chl $a$ per cell, which results in a reduced packaging effect (Greene et al. 1991; van Leeuwe and De Baar 2000) and a relative increase in light-harvesting pigments (increased ratio of total carotenoid pigments to Chl $a$ ). As a result, the Chl $a$-specific absorption cross section $\bar{a}_{\mathrm{ph}}$ significantly increases under iron limitation. As discussed, the single-cell form that dominated under iron-deplete conditions may further contribute to an increase in $\bar{a}_{\mathrm{ph}}$. The increase in absorption capacity appears to balance the reduction in photosynthetic efficiency to a large extent. If we consider growth as a function of these photosynthetic parameters we may estimate the relative carbon-normalised growth capacity (Table 2: rgc) by applying a simple relationship: $\operatorname{rgc} \approx F_{v} / F_{m^{*}} \bar{a}_{\mathrm{ph}^{*}} \mathrm{Chl} a \mathrm{cell}^{-1} / \mathrm{POC}$ cell $^{-1}$. This exercise shows that the capacity of iron-limited and iron-replete cells is almost equal: 0.13 and 0.12 , respectively. It should be noted that this only is an approach of gross growth capacity, since maintenance costs are not included in this concept. Net growth rates as determined on the basis of cell divisions are significantly higher in iron-replete cells.

The ratio HEXA/Chl $a$ was found to be twice as high in iron-limited cells compared to ironreplete cells. In previous experiments, similar high HEXA/Chl $a$ ratios were recorded (van Leeuwe and Stefels 1998). Concomitant high ratios of HEXA/FUCO under high irradiance gave rise to a hypothesis on an alternative photoprotective pigment cycle. It was suggested that in response to exposure to high irradiance the efficient light-harvesting pigment FUCO would be converted into its structural relative HEXA. The efficiency of energy transfer by HEXA has not yet been described, which leaves room for a role as energy quencher. This hypothesis could not be confirmed in our short-term experiments. The ratio of HEXA/FUCO was again higher for 
iron-limited cells, but did not vary with fluctuating irradiance levels. As for the well-established xanthophyll pigment cycle, such a relationship should have been apparent in case of an active role in photochemical quenching. The role of HEXA is still enigmatic, but an influence on energy dissipation cannot be excluded.

This study has shown that Phaeocystis antarctica can readily respond to fast changes in light climate. Iron limitation exerted stress on the cells, but due to changes in pigment composition these cells were able to acclimate and apparently did not suffer from photoinhibition. Altogether, these characteristics are vital to maintain growth in the Antarctic Ocean, where deep wind-mixed layers predominate and where low iron concentrations suppress algal growth. Under such conditions $P$. antarctica appears a successful competitor. The alga may support carbon flow within so-called retention systems. Alternatively, Phaeocystis can contribute to large carbon fluxes from the surface waters into the oceans interior. So far, very few data are available on photosynthetic responses towards variable light conditions. With this paper we hope to improve our understanding of biogeochemical cycles in the Antarctic ecosystem.

Acknowledgements We would like to thank Ronald Visser for pigment analysis and technical support. We thank Walker Smith for a critical review of the manuscript. MAvL and JS were financially supported by the Dutch Polar Programme of the Research Council for Earth and Life Sciences (ALW) of the Netherlands Organisation for Scientific Research (NWO).

\section{References}

Anderson JM, Chow WS, Park Y-I (1995) The grand design of photosynthesis: acclimation of the photosynthetic apparatus to environmental cues. Photosynth Res 46:129-139

Arrigo KR, Robinson DH, Worthen DL, Dunbar RB, DiTullio GR, VanWoert M, Lizotte MP (1999) Phytoplankton community structure and the drawdown of nutrients and $\mathrm{CO}_{2}$ in the Southern Ocean. Science 283:365-367

Crocker KM, Ondrusek ME, Petty RL, Smith RC (1995) Dimethylsulfide, algal pigment and light in an Antarctic Phaeocystis sp. bloom. Mar Biol 124:355-340

DeBaar HJW, et al (2005) Synthesis of iron fertilisation experiments: from the iron age in the age of enlightment. J Geophys Res 110:C09S16
Demmig-Adams B, Adams III WW (1996) Photoprotection and other responses of plants to high light stress. Annu Rev Plant Physiol Plant Mol Biol 43:599-626

Flameling IA (1998) Growth and photosynthesis of eukaryotic microalgae in fluctuating light conditions, induced by vertical mixing. University of Nijmegen. Thesis/Dissertation, $135 \mathrm{pp}$

Flameling I, Kromkamp J (1995) Regulation of photosynthesis of Phaeocystis globosa in fluctuating light conditions. In: Mathis P (ed) Photosynthesis: from light to biosphere. Kluwer Academic Publishers, pp 797-800

Fujiki T, Tagushi S (2002) Variability in chlorophyll $a$ specific absorption coefficient in marine phytoplankton as a function of cell size and irradiance. J Plankton Res 24(9):859-874

Geider RJ, LaRoche J (1994) The role of iron in phytoplankton photosynthesis, and the potential role of iron limitation of primary productivity in the sea. Photosynth Res 39:275-301

Geider RJ, LaRoche J, Greene RM, Olaizola M (1993) Response of the photosynthetic apparatus of Phaeodactylum tricornutum (Bacillariophyceae) to nitrate, phosphate, or iron starvation. J Phycol 29:755-766

Greene RM, Geider RJ, Falkowski PG (1991) Effect of iron limitation on photosynthesis in a marine diatom. Limnol Oceanogr 36(8):1772-1782

Han B-P, Virtanen M, Koponen J, Straskraba M (2000) Effect of photoinhibition on algal photosynthesis: a dynamic model. J Plankton Res 22:865-885

Kana TD, Geider RJ, Critchley C (1997) Regulation of photosynthetic pigments in micro-algae by multiple environmental factors: a dynamic balance hypothesis. New Phytol 137:629-638

Kana R, Lazar D, Prasil O, Naus J (2002) Experimental and theoretical studies on the excess capacity of photosystem II. Photosynth Res 72:271-284

Krause GH, Weis E (1991) Chlorophyll fluorescence and photosynthesis: the basics. Annu Rev Plant Physiol Plant Mol Biol 42:313-349

Kruskopf M, Flynn KJ (2006) Chlorophyll content and fluorescence responses cannot be used to gauge reliable phytoplankton biomass, nutrient status or growth rate. New Phytol 169:525-537

Larkum AWD, Douglas SE, Raven JA (eds) (2003) Photosynthesis in algae. Kluwer Academic Publishers, Dordrecht, $480 \mathrm{pp}$

Martin JH, Gordon RM, Fitzwater SE (1990) Iron in Antarctic waters. Nature 345:156-158

Meyer AA, Tackx M, Daro N (2000) Xanthophyll cycling in Phaeocystis globosa and Thalassiosira sp.: a possible mechanism for species succession. J Sea Res 43:373-384

Mitchell BG, Brody EA (1991) Light limitation of phytoplankton biomass and macronutrient utilization in the Southern Ocean. Limnol Oceanogr 36:1662-1677

Mohanty N, Gilmore AM, Yamamoto HY (1995) Mechanism of non-photochemical chlorophyll fluorescence quenching. II. Resolution of rapidly reversible absorbance changes at $530 \mathrm{~nm}$ and fluorescence quenching by the effects of antimycin, dibucaine and 
cation exchanger, A23187. Aust J Plant Physiol 22:239-247

Moisan TA, Mitchell BG (1999) Photopysiological acclimation of Phaeocystis antarctica Karsten under light limitation. Limnol Oceanogr 44(2):247-288

Moisan TA, Olaizola M, Mitchell BG (1998) Xanthophyll cycling in Phaeocystis antarctica: changes in cellular fluorescence. Mar Ecol Prog Ser 169:113-121

Morales F, Abadia A, Abadia J (1998) Photosynthesis, quenching of chlorophyll fluorescence and thermal energy dissipation in iron-deficient sugar beet leaves. Aust J Plant Physiol 25:403-412

Morel A, Bricaud A (1981) Theoretical results concerning light absorption in a discrete medium, and application to specific absorption of phytoplankton. Deep-Sea Res 28A(11): 1375-1393

Morel FMM, Rueter JG, Anderson DM, Guillard RRL (1979) AQUIL: a chemically defined phytoplankton culture medium for trace metals. J Phycol 15:135-141

Muller P, Li X-P, Niyogi KK (2001) Non-photochemical quenching. A response to excess light energy. Plant Physiol 125:1558-1566

Nolting RF, de Jong JTM (1994) Sampling and analytical methods for the determination of trace metals in surface seawater. Intern $\mathrm{J}$ Environ Anal Chem 57:189-196

Olaizola M, La Roche J, Kolber Z, Falkowski PG (1994) Non-photochemical fluorescence quenching and the diadinoxanthin cycle in a marine diatom. Photosynth Res 41:357-370

Pascal A et al (2005) Molecular basis of photoprotection and control of photosynthetic light-harvesting. Nature 436:134-137

Sedwick PN, Garcia NS, Riseman SF, Marsay CM, DiTullio GR (2006) Evidence for high iron requirements of colonial Phaeocystis antarctica at low irradiance Biogeochemistry, this volume

Smith WO, Carlson CA, Ducklow HW, Hansell DA (1998) Growth dynamics of Phaeocystis antarctica-dominated plankton assemblages from the Ross Sea. Mar Ecol Prog Ser 168:229-244

Stefels J, van Leeuwe MA (1998) Effects of iron and light stress on the biochemical composition of Antarctic Phaeocystis sp. (Prymnesiophyceae). I. Intracellular DMSP concentrations. J Phycol 34:486-495

Trtílek M, Kramer DM, Koblízek M, Nedbal L (1997) Dual-modulation LED kinetic fluorometer. J Lum 72-74:597-599

Vaillancourt RD, Sambrotto RN, Green S, Matsuda A (2003) Phytoplankotn biomass and photosynthetic competency in the summertime Metz Glacier Region of East Antarctica. Deep-Sea Res II 50:1415-1440

van Leeuwe MA, De Baar HJW (2000) Photoacclimation by the Antarctic flagellate Pyramimonas sp. (Prasinophyceae) in response to iron limitation. Eur J Phyol 35:295-303

van Leeuwe MA, Scharek R, de Baar HJW, de Jong JTM, Goeyens L (1997) Iron enrichment experiments in the Southern Ocean: physiological responses of plankton communities. Deep-Sea Res II 44:189-207

van Leeuwe MA, Stefels J (1998) Effects of iron and light stress on the biochemical composition of Antarctic Phaeocystis sp. (Prymnesiophyceae). II. Pigment composition. J Phycol 34:496-503

van Leeuwe MA, van Sikkelerus B, Gieskes WWC, Stefels J (2005) Taxon-specific differences in photoacclimation to fluctuating irradiances in an Antarctic diatom and a green flagellate. Mar Ecol Prog Ser 288:9-19

van Leeuwe MA, Villerius LA, Roggeveld J, Visser RJW, Stefels J (2006) An optimized method for automated analysis of algal pigments by HPLC. Mar Chem 102:267-275

van Oijen T, van Leeuwe MA, Gieskes WWC, de Baar HJW (2004) Effect of iron limitation on photosynthesis and carbohydrate metabolism in the Antarctic diatom Chaetoceros brevis (Bacillariophyceae). Eur J Phycol 39:161-171 